\title{
Aspectos e Problemas da Paisagem no Desenho da Pequena e Média Cidade no Estado de São Paulo
}

\author{
Paulo Celso Dornelles Del Picchia
}

\begin{abstract}
Aborda aspectos e problemas do desenho da paisagem das cidades pequenas e médias no estado de São Paulo baseando-se no exemplo das cidades de Brodowski, Batatais e Franca. Constata que a arquitetura paisagística foi inicialmente praticada por especialistas, destacando a presença da topiaria no desenho dos jardins. Mostra aspectos do desenho urbano e salienta a sua fragilidade diante dos processos de crescimento e mudanças urbanas. Alerta para a necessidade de um profissional especializado nos desenhos urbanos e da paisagem.
\end{abstract}

\section{Abstract}

It brings up aspects and problems of landscape design in small and medium size towns in the state of São Paulo, taking as examples the towns of Brodowski, Batatais and Franca. It shows that landscape architecture in these towns was at first executed by specialists, emphasizing its fragility in facing urban growth and change. It emphasizes the need for a professional specialist on urban and landscape design.
Antigo elaborado com base na Dissentação de Mestrado "Brodowski", apresentada em agosto de 1991.

Orientador: Prof. Dr. Eduardo Corona. 


\section{Introdução}

Ao elaborarmos a nossa dissertação de mestrado "Brodowski, Batatais e Franca: análise da paisagem urbana" (Del Picchia, 1991), pudemos visualizar uma série de aspectos da paisagem urbana e também identificar uma série de problemas no desenho dessas cidades.

\section{A Cidade como uma Colcha de Retalhos}

Batatais e Franca são cidades que surgiram como pousos ao longo do caminho dos Guayases, meio de penetraçāo no interior do Brasil desde os tempos coloniais, aberto no processo de interiorização da colonização do Brasil na procura de riquezas e minerais preciosos. Brodowski, ao contrário, originou-se do avanço da ferrovia no período da cultura cafeeira. Apesar dessa diferença, as três cidades guardam as características da urbanização do período cafeeiro, o que as aproxima, como desenho urbano, das outras cidades paulistas surgidas no mesmo periodo.

Se apreciarmos os mapas dessas cidades veremos que à malha viária em tabuleiro de xadrez do núcleo inicial foram se acrescentando outros quadriculados, que para melhor aproveitamento em lotes foram seguindo a orientação das bordas das glebas rurais, que com o desenvolvimento dessas cidades foram se incorporando ao tecido urbano, orientação essa diversa da do núcleo inicial. Isto levou à formação de uma colcha de retalhos, retalhos que ficam bastante evidentes nos mapas dessas cidades graças à diferente orientaçāo do traçado das ruas dos diversos tabuleiros de xadrez em que se constituem os novos loteamentos. (Saia, 1972, p. 202)

Essa forma de desenho urbano, por um lado, trouxe problemas funcionais, criando ruas de declividade acentuada, dificultando o aproveitamento do lote, causando problemas de erosão acentuada; por outro lado, na nossa dissertação demonstramos que a junção desses tabuleiros de xadrez favoreceu o aparecimento de qualidades plásticas na forma urbana, que seriam muito difíceis de serem criadas num traçado de ruas que se cruzam ortogonalmente, com casario monótono construído no alinhamento da rua, como acontece o mais das vezes nessas cidades. Essa junçāo irregular dos tabuleiros de xadrez dos loteamentos, aliada à topografia, criou condiçōes de quebrar a monotonia do desenho urbano, dando aspectos individualizadores a um tecido urbano de outro modo pouco diversificado.

\section{Fragilidade do Desenho Urbano}

No momento em que o urbanismo passou a preocupar-se com a memória urbana, a preservação da paisagem urbana deve constituir-se numa preocupação do urbanismo. O que vemos entre nós é um despreparo no que se refere à paisagem urbana. Já conseguimos tombar edifícios, mas criamos dispositivos puramente burocráticos para tombar os arredores desses edifícios. Nāo temos procedimentos de trabalho para avaliar o caráter da paisagem urbana e, assim, ter os elementos necessários para gerenciar o crescimento de nossas cidades preservando a paisagem. A cidade de Berlim, na Alemanha, tem entre os mapas de seu Umweltatlas (sistema informatizado inteligente de dados ambientais), um mapa intitulado Stadtbild (Paisagem Urbana), pelo qual se pode 
reconhecer o caráter da paisagem de cada pedaço da cidade. (Stellpflug et al., 1985)

Os nossos planos diretores urbanos são pensados bidimensionalmente. Em nossa dissertaçāo constatamos a influência da topografia na caracterizaçāo da paisagem urbana, na determinação de marcos da paisagem, na constituição de panoramas. Notamos, também, a fragilidade da paisagem diante da indiscriminada verticalizaçāo que se inicia em nossas cidades e que em São Paulo, a capital, já levou a uma total descaracterizaçāo da paisagem urbana, destruindo marcos e referências tradicionais da cidade, de modo que hoje é difícil orientarse na cidade.

George R. Collins e Christiane Crasemann Collins (Collins, Collins, 1965) comentando a obra de Camillo Sitte (Sitte, 1983) dizem: "Ele recomendou com insistência o uso do Bebauungsplan (que chamou de Verbauungsplan), isto é, uma planta da cidade concebida em três dimensōes, mostrando a elevação dos prédios que estão para ser edificados nos terrenos. O Bebauungsplan conseqüentemente tornou-se a base para uma rigorosa e mais detalhada regulamentação da construção, especialmente tendo-se em vista o zoneamento por altura; dai os planejadores alemães tornarem-se cada vez mais interessados em seu uso nos anos 1890." (Collins, Collins, 1965, p. 17) Entre nós já se elaborou esse tipo de plano no desenho urbano como podemos constatar pelos desenhos que encontramos no livro "Os Melhoramentos de São Paulo" (Prestes Maia, 1945), notadamente o projeto da avenida Anhangabaú (op. cit., fig. 94). Retomar esses procedimentos e, hoje, já com a ajuda da computação gráfica, seria de grande utilidade para que o desenvolvimento urbano não leve a uma total descaracterizaçāo de nossas cidades, transformando-as em cidades sem memória.

\section{O Surgimento das Áreas Verdes}

Os espaços de domínio e uso comum do povo na cidade brasileira sofreram uma lenta e progressiva laicização (Marx, 1989, p. 199); os largos diante das igrejas antes reservados às festas religiosas passam ao uso profano.

Ao estudarmos Brodowski vemos que sua origem não é a do "patrimônio religioso" (Deffontaines, julho 1944) e sim constitui-se num "patrimônio leigo" (Deffontaines, julho 1944), tendo-se originado da construção de uma estação de estrada de ferro em terras de um fazendeiro de café que loteia as terras de sua fazenda junto a essa estação. Ao proceder a esse loteamento o fazendeiro já reservou duas áreas ao patrimônio público, uma junto à estação e outra em área próxima. Quando Brodowski vem a ter uma igreja (isto se dá três anos depois da fundação da cidade), esta foi construída em terreno próprio, dentro da malha urbana. (Corrêa, 1986)

As praças em Brodowski representam um novo conceito de espaço de uso público, um espaço puramente leigo, desvinculado da função religiosa. Acreditamos que elas estejam ligadas aos conceitos do urbanismo sanitarista do séc. XIX, tão bem analisado e criticado por Camillo Sitte. (Sitte, 1983) Constituem um espaço para a recreação e saúde da população urbana e não mais um espaço para festas religiosas. São as primeiras áreas verdes urbanas como hoje as entendemos. Como outro exemplo poderiamos citar o Parque Público 
na cidade do Rio Claro, no interior de São Paulo, cujo jardim foi projeto da firma Dierberger. (Dierberger \& Cia. 1928)

\section{A Cidade do Café, uma Cidade Leiga}

Em Batatais e Franca, "patrimônios religiosos" (Deffontaines, julho 1944), as praças de matriz, praça Cônego Joaquim Alves e praça N. Sra. da Conceição, são o centro da freguesia e núcleo da cidade, comprometidas por isso com o urbanismo colonial, tendo se laicizado no decorrer do tempo. Essas cidades, porém, tiveram até o princípio do séc. XIX um desenvolvimento incipiente conforme podemos perceber pelo relato de viajantes (Saint-Hilaire, São Paulo nos tempos coloniais, cit. por Tambellini, 1939, p. 143-144; Saint-Hilaire, Viagem à província de São Paulo, cit. por Chiachiri Filho, 1973 Parte A, Cap.II, "A vila"). Na segunda metade do séc. $X I X$ e início do séc. $X X$, graças à cultura cafeeira, essas cidades se expandem e se conformam da mesma maneira que Brodowski. Se a arquitetura na segunda metade do séc. XIX sofreu mudanças graças às transformaçōes sociais e econômicas que levaram ao surgimento do Ecletismo e a novas soluções de implantaçāo no lote urbano, a maneira de se encarar a cidade também mudou. Nāo estamos mais diante do traçado hipodâmico de inspiração renascentista dos tempos coloniais (Reis Filho, 1968, p. 128), mas parece-nos sentir a influência do urbanismo racional e sanitarista do séc. XIX europeu, através das ruas amplas e arborizadas, da reserva de áreas verdes (praças), do traçado urbano de motivação laica.

\section{Arquitetura Paisagística}

As praças mais antigas de nossas cidades do interior são exemplos da arte paisagística corrente no princípio do séc. $X X$, cujos exemplos encontramos na obra de Jules Vacherot. (Vacherot, 1909) Segundo ele a arte dos jardins comporta três estilos: o primeiro é o estilo clássico ou regular (comumente chamado "jardim francês"), o segundo é o estilo romântico ou paisagista (comumente chamado "jardim inglês"), o terceiro é o estilo composto que compreende partes do estilo clássico e partes do estilo romântico em proporçōes iguais. Muitas das construções de jardim ilustradas por ele, como os parapeitos imitando troncos e as imitaçōes de rochas, todas em argamassa de concreto, vamos encontrar na praça da República e no jardim da Luz na cidade de São Paulo.

Mas, o que nos chama a atenção nas praças das cidades do interior do estado de São Paulo é a presença da topiaria. Em Batatais encontramos uma praça que nāo podemos enquadrar no aludido "estilo francês" pois apesar de sua construção geométrica, falta-lhe um eixo de perspectiva dominante e faltamIhe os "parterres de broderie" O trabalho de um jardineiro de origem italiana, Jorge Sandrin (Del Picchia, 1991, p. 33 e 34), paisagista ou melhor, topiário, como queriam os romanos (Gromort, 1953), com as bordaduras dos canteiros podadas de forma escalonada e a composição centrada no coreto, lembra muito os jardins do Renascimento italiano. Conforme apuramos em Batatais, Jorge Sandrin tinha uma prancheta de desenho e concebia seus jardins através de desenhos, projetos. O mesmo nos afirmou o filho de Antônio Etzel, Eduardo Etzel, em depoimento que colhemos, eu e a historiógrafa do Departamento de Parques e Áreas Verdes da Prefeitura de São Paulo, Maria das 
Graças Fontes de Almeida. Segundo Eduardo, seu pai, que foi encarregado dos jardins públicos da cidade de São Paulo (Etzel, 1982), também tinha uma prancheta de desenho onde projetava os seus jardins, afirmando-nos, ainda, que Antônio Etzel, um italiano de cidadania austríaca, natural de Trento, teria se diplomado em horticultura ou paisagismo na sua cidade natal, dizendo ter um diploma que não pudemos ver. Tudo isto parece demonstrar que esses jardineiros traziam uma sólida formação que infelizmente seus sucessores não tiveram, o que explica o abandono ou mal manejo que muitas áreas verdes no interior do estado e mesmo na capital têm tido.

\section{Publicidade}

A publicidade através dos anúncios nas fachadas dos prédios sofreu um incremento nos últimos tempos com o advento de novos materiais de construção e foi favorecida, talvez, pela fragilizaçāo do gosto arquitetônico devida ao movimento moderno na arquitetura que destruiu os velhos cânones e modelos em que esta arte estava baseada, instituindo uma liberdade de projeto que foi mal apropriada pela população. Através de remanescentes de anúncios indicativos de atividades de estabelecimentos comerciais, a maioria em bandeira, de pequenas dimensões, que encontramos nas cidades que analisamos em nossa dissertação de mestrado, pudemos verificar que eles respeitavam as características arquitetônicas das edificações e jamais interferiam negativamente na paisagem urbana. O mesmo não ocorre com os anúncios mais recentes que se apõem às fachadas, encobrindo-as e descaracterizando-as estetica e funcionalmente.

\section{Natureza e Paisagem Urbana}

Num mundo que não possibilita mais fronteiras entre a paisagem natural e a paisagem cultural, entre paisagem urbana e paisagem rural, devido à expansão da urbanização, numa região em que as conurbaçōes são cada vez mais freqüentes, não mais podemos ficar alheios às idéias de preservação da biodiversidade em meio urbano. Constatamos a incapacidade de arquitetos e engenheiros envolvidos no desenho urbano de incorporar aos seus projetos a preservação de elementos naturais à paisagem urbana. Estamos sempre diante de projetos desnaturalizantes como canalizações de córregos, transformações de fundos de vale em avenidas, terraplenagens descaracterizadoras da topografia, avanço das cidades sobre manchas de solos férteis raros, uso de cada vez menos espécies vegetais, a maioria exóticas, com sérios prejuízos à fauna e à preservação da natureza tão seriamente ameaçada pelo avanço da urbanização.

Falta-nos a idéia do planejamento da paisagem, como o da República Federal da Alemanha, onde é feita a determinação dos potenciais da natureza, delimitando os sítios que são importantes para as espécies e biótipos, para a recreação ligada à natureza, para a regulação e regeneração do solo, água, ar e clima. O processo de planejamento da paisagem deve estabelecer metas, elaborando modelos para o desenvolvimento espacial do ponto de vista de proteção à natureza e gerenciamento da paisagem. Deve promover a avaliação do impacto dos usos do solo nos ecossistemas. Deve estabelecer programas de ação desenvolvendo medidas para evitar, reduzir, mitigar e compensar 
os impactos causados pelos usos do solo existentes e propostos sobre os potenciais da natureza. (Kiemstedt, H. et al. 1990)

\section{Desenho Urbano não se Improvisa}

No passado os profissionais que atuavam na arquitetura e no desenho urbano eram especializados, sabiam e tinham técnicas para sua açāo.

No caso do chamado paisagismo, nome genérico dado no Brasil a atuaçōes que vāo desde a jardinagem até às atividades de gerenciamento e proteção à natureza (o que demonstra uma incompreensão das escalas ao se usarem os mesmos métodos e procedimentos na abordagem das diferentes escalas de trabalho), isto tem levado às distorçōes que apontamos. Falta um profissional competente. Não é mais possível improvisar um especialista em edificações como o engenheiro civil ou o arquiteto paisagista ou urbanista. Nem mesmo confundir o engenheiro sanitarista, capaz de monitorar os casos de poluição, com o especialista em gerenciamento da paisagem ou mesmo usar geólogos ou geógrafos para esse fim.

Um novo profissional precisa ser formado nas universidades brasileiras para as diversas atuações na construção e proteção da paisagem. O campo de trabaIho é novo e apresenta desafios que as formaçōes que apontamos acima não serāo capazes de resolver. É preciso compreender que os enfoques dessas profissōes sāo outros e que é impossivel ser um factotum, um homem do Renascimento nos dias que correm.

\section{Bibliografia}

CHIACHIRI FILHO, José. Do sertāo do rio Pardo à Vila Franca do Imperador. Franca, 1973. 244p. il. Tese (Doutoramento). Faculdade de Filosofia Ciências e Letras de Franca, FFCL - Franca.

COLLINS, George R., COLLINS, Christiane Crasemann. Camillo Sitte and the birth of modern city planning. New York: Random House, 1965. 232 p. il.

CORREAA, Ariovaldo. Brodowski: minha terra e minha gente. 1. ed. São Paulo: Pannartz, 1986. 360 p. il.

DEFFONTAINES, Pierre. Como se constituiu no Brasil a rede de cidades. Boletim geográfico, Rio de Janeiro, Conselho Nacional de Geografia, n. 15, v. 2, p. 299-308, jul. 1944.

DEL PICCHIA, Paulo Celso Dornelles. Brodowski, Batatais e Franca: análise da paisagem urbana. São Paulo, 1991. 2v. il. Dissertaçāo (Mestrado). Faculdade de Arquitetura e Urbanismo, Universidade de São Paulo.

DIERBERGER \& CIA. Arte e jardim. São Paulo, maio 1928.

ETZEL, Eduardo. O verde na cidade de Sāo Paulo. Revista do Arquivo Municipal. São Paulo, n. 195, p. 51-76, 1982.

GROMORT, Georges. L'art des jardins 2. ed. Paris: Vincent Freal et Cie., 1953. v. 1. il.

KIEMSTEDT, $\mathrm{H}$. et al. Landscape planning in the Federal Republic of Germany. In: CONFERÉNCIA INTERNACIONAL: A CONTRIBUIÇĀO DO PLANEJAMENTO DA PAISAGEM PARA A PROTEÇẢO DO MEIO AMBIENTE. Hanovre, Universidade de Hanovre, junho 1990.

MARX, Murillo. Nosso chão: do sagrado ao profano. Sāo Paulo: Editora da Universidade de São Paulo, 1989. 219p. il. 
PRESTES MAIA, Francisco. Os melhoramentos de São Paulo. 2. ed. São Paulo, Prefeitura Municipal de São Paulo, 1945. 40p. il.

REIS FILHO, Nestor Goulart. Contribuição ao estudo da evolução urbana do Brasil (1500/1720). Sāo Paulo: Livraria Pioneira Editora/Editora da Universidade de São Paulo, 1968. 235p. il.

SAIA, Luis. Morada Paulista. São Paulo: Perspectiva, 1972. 311p. il.

SITTE, Camillo. Der Städtebau: nach seinen künstlerischen Gründsätzen, vermehrt um "Grossstadtgrün". Braunschweig/Wiesbaden, Friedr. Vieweg \& Sohn, 1983 (Reimpressāo da 4. Edição de 1909). 216p. il.

STELLPFLUG et al. Umweltatlas. Berlim, Senat für Stadtentwicklung und Umwelt,1985. $8 \mathrm{~V}$.

TAMBELLINI, J. Machado. A freguesia dos Batatais. Revista dos Tribunaes. São Paulo, Empresa Graphica, 1939.

VACHEROT, Jules. Les Parcs et jardins au commencement du XX siècle. Paris: Octave Doin Editeur, Librairie Agricole, 1909. 475p. il. 